\title{
Five Easy Pieces
}

\author{
By Rod Stoneman \\ Spring 2004 Issue of KINEMA
}

THIS BRIEF and itinerate survey of the airwave spectrum, a somewhat arbitrary scan across the audio visual radar, takes a glancing read of some current films and television programmes. There should never be any inhibition or snobbery about the range or pluralism of the material we take seriously, in fact there is an imperative to attend to the things that most people watch. Even if these five fragments, very different pieces from different places in film and television, cannot possibly add up to a balanced overview, they form some part of the pattern of how things are now.

\section{1) Kill Bill}

As the opening credits announce, this is indeed the fourth film by Quentin Tarantino; (it's worth remembering that Ford, Hawks and Huston used to produce that number every couple of years rather than over a decade and a half). But this is part of the enhanced self-promotion of the exemplar director of post modernism (or PoMo as it was appropriately called) in cinema. Of course there is the display of a high level of accomplished aesthetic play: from the yellow design to stylish, balletic violence that can never be described as visceral; maybe Tarantino remembers Godard's line "It's not blood - it's red paint"; after all he adopted the title of one of Godard's early films, Bande à part, as his production company name.

In a sense it was evident from Reservoir Dogs, Tarantino's first film, that he is really a formalist or mannerist - the long inconsequential dialogue over the opening sequence and the remarkable generic subversion making for a heist movie without a heist. Beneath the superficial violent style of Pulp Fiction is a delight in formal devices and in 90 degree narrative turns; Jackie Brown and Kill Bill show the cinephile who worked in the downtown LA video shop fascinated to play through a parody of other genres; this time with the inclusion of Kung-fu and Japanese animation. In contrast to most of the generic films he parodies, there is a lack of emotion or engagement with spectacular, excessive "violence" overlaying a tenuous plot - a blood-soaked protracted nothingness that may express some underlying rage for revenge after the "great castration" of $9 / 11$.

If all this adds up to a fascination with form and a dearth of "something to say", it is not to imply that all films should bear weighty social themes, but that Tarantino's work is an exaggerated version, consonant with much new American cinema, of film more concerned with an endless surface of style than substance.

Towards the end of the post-production process, Miramax suggested splitting the movie into two separate halves, thus doubling box office return rather than suffering the inevitably reduced take of a single long film which could only be shown once an evening in cinemas. This connects with the overt manipulation of the marketing of "Tarantino" and also confirms the weak narrative base of the piece - a continuous spectacular display that can be cut into sections at any point...

\section{2) Jackass the Movie}

Jackass begins with the marvel of Spike Jonze's opening sequence: an early collaborator with the MTV series, Jonze creates an exhilarating introduction - the hilarity of nine of the Jackass group racing out of control in an outsized supermarket trolley, to the strains of Carl Orff's rousing Carmina Burana, rocketing downhill through volleys of bricks to collide with a fruit and vegetable stall.

Jackass emerged out of skateboard culture (a magazine called Big Brother); described self-deprecatingly by its creators as "moronic antics", it became a worldwide phenomenon via an MTV series. The movie assembles a succession of scenes in which adolescent lads perform the same stunts and tricks, often hurting themselves, as in the television series. Their play takes more or less dangerous, harmful, painful forms - the hazardous and deliberate crashes of "Golf Cart Antics" come close to serious injury. There's frolicking with faeces and much of the humour is predictably anal: "Bottle Rocket" has the gang firing fireworks from a rectum into the night sky above Tokyo and "Butt X-Ray" laboriously records an unfortunate inserting a toy car in his anus. 
There is something strange in this confluence of masochism and narcissism, which also characterised David Blaine's Above the Below. Johnny Knoxville articulates the Jackass stance exactly: "I can't spell narcissistic, but that's what I am!" In previous eras a group of white young males might have been the shock troops of social change, but instead we witness an introverted displacement of their attention to the pleasure of hurting themselves, flirting with danger and risking injury for its own sake.

Their stunts are a self-absorbed exhibition of the strange rituals of adolescent masculinity. Their forays with supermarket trolleys (the iconic Jackass vehicle), are in stark contrast to those apocryphal Situationists / anarchists who, a generation ago, went into a department store dressed as Santa Clauses and distributed toys to small children - leading to a hiatus and inevitable scenes of distress as security staff had to grab the toys back from crying infants... The nearest Jackass gets to direct social action is the "Air horn at Golf Course" sequence where they hide in the bushes and let loose loud blasts from a fog horn to disrupt and infuriate a group of golfers (wearing the inevitable check slacks and red jumpers) at the moment they attempt to tee off. It's a remarkably mild and mediocre attempt to épater la bourgeoisie!

\section{3) The Office}

The success of the BBC series The Office must result from both the painful precision of its humour and its play with the almost universal experience of office life. As everyone knows, English culture is "all about class" and the specifics of this excursion into workplace HR dynamics offers an exemplary satire that works through both class and gender relations, and the graded levels and movements between them.

The delusions of the eccentric Gareth play alongside Tim's grounded no-nonsense views; but then Tim, in his movement for promotion, sets aside his independence and idealism and, to Dawn's disconcertion, seems to adopt his boss's voice and mannerisms. Despite her misbegotten loyalty to her oppressive fiancé Lee, Dawn's perceptive scepticism about her boss and the long looks she throws at his embarrassing antics represent a centre of gravity in the series. The last two "extra" episodes shown at Xmas 2003 offer redemption for both David Brent, who finds a semi-sensible potential partner at the Xmas party, and Dawn as she abandons Lee and departs for self-realisation as a graphic illustrator with Tim.

The penetrating acerbic wit of the two series and two extra episodes is almost unbearably excruciating. It is rare to encounter comedy so consistently painful and hilarious - The Office engenders oxymoronic designations through its profoundly accurate and discomforting satire. There is a point at which the savage satire of ineptitude enables that clowning to become poignant and meaningful, as in the well-intentioned but brutal clumsiness of Ricky Gervais' monstrous manager explaining racism to his black colleagues - bringing unconscious ideology into sharp focus.

The series also provides an implicit genre critique of reality television; a sitcom without a laugh track, it inhabits that same tension between improvisation and pre-scripted form as Mike Leigh. The Office's suburban comedy explicitly connects it with Betjeman's Slough poem and adds a sharper, contemporary satire of human weakness and venality. It shows that the most substantial programmes can be the most entertaining at the same time...

\section{4) Big Brother 4 and Reality Television}

In its initial versions Channel Four's Big Brother must be given credit for extending the boundaries of television, offering continuous ancillary live streaming of the group on the internet which ideally suited their CCTV confinement.

The audience's role in the competition between individuals, and its involvement in voting to exclude inmates made the series even more of an event; although inducement to increase phone and television companies' income by making calls is not real participation. The alternation of "celebrities" with pre-established media profiles and "ordinary" people plays into this as new celebs are created in the process: John Tickle from BB 4 becomes a presenter and Jade Goody from BB 3 participates in Celebrity Wife Swap.

The dramatic focus of the regular expulsions from the garden of Eden breaks into the banality of the everyday. Reality tv dwells on endless moments of triviality - Cameron washing his hair in BB 4 or Lord Brocket flirting with his social inferiors in I'm a Celebrity...Get Me Out of Here (treating Jordan as his ancestors treated their serving wenches). But the disingenuous nature of each self-conscious performance, positioning itself in relation to the hazardous process of nominations and exclusions, renders the personal interactions false. The 
programmes efface their extensive production teams and elaborate, manipulative process; the semblance of the spontaneous "reality" is of course an elaborately orchestrated and constructed representation. The same is true of psychodramas as different as I'm a Celebrity... which deploys the self-humiliation of Fear Factor tests in more exotic climes or RTE's ill-fated nautical replication, Cabin Fever.

Sadly, Big Brother has also played its role in the erasure of Channel Four's variegated diet. This is part of the wider process of decline of public service television highlighted when Brookside, the Channel's original innovative soap, was unceremoniously removed last year. Jimmy Corkhill's rant in the final episode denounced the state of contemporary television, blaming television executives "totally isolated in their glass offices in London." After the lynching of drug dealer Jack Michaelson (as in Michael Jackson) Jimmy talks directly: "I can remember when telly meant something. You could watch a documentary, you watched a drama and they made you think about life and not whether you had the right wallpaper to match your kecks."

As Big Brother indicates, the narrative addiction on which event television depends can work equally well with the categories of "factual" or "fictional" content. The flood of information through all media that accompanies the death of Diana or the invasion of Iraq creates the same narrative compulsion as a high profile storyline in Emmerdale or First City. O tempora, o mores!

\section{5) Eloge d'Amour}

A public screening at Rotterdam Film Festival in January 2003 showed J-L G is still dividing the audience: at $10 \mathrm{pm}$ the large auditorium was full; after half an hour there was a thin but continuous stream of walkouts; the film finished at midnight, when it was given a standing ovation by the two thirds of the audience that remained. Many will now see it on DVD - a format and an exhibition context which allows access to a much greater variety of films, formerly restricted, including esoteric minority films such as this.

Godard's film may well be available but it is not necessarily accessible. Its intricate fragmentary forms continue to be opaque to many: the various characters who all talk with Godard's voice; the movement from black and white film into digital colour - video and celluloid touching on two areas of his work over the last decades.

As Colin MacCabe's recent biography, Godard - A Portrait of the Artist at Seventy, indicates, Godard's trajectory has involved reinventing himself three or four times. The solipsism of his subjectivity has led Godard from European art house to the avant garde. Audiences, meanwhile, have shifted towards studio films and Godard, with characteristic dark irony, has two children in Breton national dress knock at the front door of the house with a petition to have The Matrix dubbed into the Breton language... As the audience retracts, even a screening in such a congenial context as the Rotterdam Festival shows the limitations of the available audience for "difficult" esoteric work...

\section{Notes}

This partial scan of the airwaves offers five very different glimpses of the arrangements of our times. In the disparate contexts of a popular comedy like The Office on television or the esoteric space of Eloge D'Amour on DVD, there are signs of the movement of imagination and irony. This stands in contrast to the relentless trivialisation of much television and cinema.

Jackass and Big Brother sustain the culture of narcissism in our spectacular society. As DBC Pierre suggested on RTE radio when his Booker prize was announced, our economies and cultures are based on material dissatisfaction and the compulsion to acquire, to perform and possess. Television, films and advertising imagery work to position the spectator and replicate forms of need as part of the culture of narcissism; the emotional exhibitionism and self-absorption that power the motor of consumer desire.

An overall convergence of powerful forms of marketing takes place, leading to a strong centripetal draw of attention. Across time, marketing has affected people's taste; there is a danger that, as more people become interested in fewer things, diversity and difference in the domain of television and cinema are being severely reduced.

There is also the possibility of repeating the situation which has developed over the past century in liter- 
ature - at exactly the point when western societies built formal education systems which delivered almost universal literacy, the range of reading that most people desire (once they are outside institutional education) excludes relevant or contemporary writing completely. Media education should encourage a wider audience towards diverse fare rather than, to take a proximate example, reproducing the sad effect of a succession of governments' approach to the preservation and extension of the Irish language here, where an unwieldy and inflexible pedagogy has had a counter effect of discouragement. As Paul Mercier's sharp shorts, Lipservice and Tubberware, suggest, the language survives despite, not because of, official policies and practices.

We might think of new approaches to the making and the "reading" of films and television that could counteract the distressing decline in audiovisual diversity and availability.

(This article also appeared in Film Ireland 97)

\section{Author Information}

Rod STONEMAN is Director to Huston School of Film and Digital Media, National University of Ireland in Galway. He previously served as Chief Executive of the Irish Film Board and a deputy commissioning editor of independent film and video at Channel Four. He has made several independent programmes for television (including "Between Object and Image," "Ireland: The Silent Voices," and "Italy: The Image Business"), written for Screen, Sight and Sound, Framework, and Afterimage. 